\title{
Complete Response and Long-Term Survival (>20 Years) of a Child with Tectal Glioma: A Case Report
}

\author{
Stanislaw R. Burzynski Gregory S. Burzynski Tomasz J. Janicki Ania Marszalek \\ Burzynski Clinic, Houston, Tex., USA
}

\section{Established Facts}

- Tectal glioma is the smallest deadly tumor in the body.

- There is no curative treatment.

\section{Novel Insights}

- This is the first report of effective treatment for tectal glioma.

- The treatment with antineoplastons accomplished over 12 years of tumor-free survival.

\section{Key Words}

Antineoplastons A10 and AS2-1 · Brain tumor · Brainstem glioma $\cdot$ Phase II trial $\cdot$ Tectal glioma

\begin{abstract}
Tectal glioma is a midbrain tumor. The patient generally presents with symptoms related to increased intracranial pressure and requires treatment for hydrocephalus. No effective pharmacological treatments have yet been introduced. This report discusses a case of a 13-year-old male diagnosed with tectal glioma who obtained a complete response and long-term survival after the treatment with antineoplastons (ANP) in phase II trial. Prior treatment consisted of placement of a ventriculoperitoneal shunt. After
\end{abstract}

6 years of stabilization there had been an increase in tumor size with signs of malignant transformation. The patient received treatment with ANP A10 and AS2-1 infusions for 20 months, obtained a complete response, and was switched to maintenance with ANP capsules. All treatments were discontinued in December 2003. Adverse events according to CTCAE v3.0 included: hypernatremia (two events of grade 3, one event of grade 2, four events of grade 1), one case of fatigue (grade 2), and one allergic reaction (grade 1). Currently, over 20 years from his diagnosis and over 13 years from treatment start he is symptom-free and leads a normal life. This report indicates that it is possible to obtain longterm survival of a child with tectal glioma with currently available investigational treatment.

(c) 2015 S. Karger AG, Basel

\begin{tabular}{ll}
\hline KARGER 125\% & $\begin{array}{l}\text { (1) 2015 S. Karger AG, Basel } \\
\text { 1016-2291/15/0502-0099\$39.50/0 Openger }\end{array}$ \\
$\begin{array}{l}\text { E-Mail karger@karger.com } \\
\text { www.karger.com/pne }\end{array}$ & $\begin{array}{l}\text { This is an Open Access article licensed under the terms of the } \\
\text { Creative Commons Attribution-NonCommercial 3.0 Un- } \\
\text { ported license (CC BY-NC) (www.karger.com/OA-license), } \\
\text { applicable to the online version of the article only. Distribu- } \\
\text { tion permitted for non-commercial purposes only. }\end{array}$
\end{tabular}

Gregory S. Burzynski, MD

Burzynski Clinic

9432 Katy Freeway

Houston, TX 77055 (USA)

E-Mail gsb@burzynskiclinic.com 


\section{Introduction}

Tectal glioma is a subtype of midbrain brainstem glioma which typically represents an exophytic mass extending from the quadrigeminal plate [1]. Histologically it includes pilocytic, fibrillary, low-grade or anaplastic astrocytoma [2]. The patients generally present with symptoms related to increased intracranial pressure and require effective treatment for hydrocephalus [3]. No effective pharmacological treatments have yet been recommended. Here we discuss a case of tectal glioma with long-term overall survival and a complete response (CR) after treatment with antineoplastons (ANP), which are synthetic analogs of naturally occurring amino acid derivatives that have inhibitory effects on neoplastic growth $[4,5]$.

\section{Case Report}

A 20-year-old Caucasian male (date of birth February 19, 1981) presented to Burzynski Clinic in August 2001, with a long history of brain tumor. In January 1994, the patient was evaluated for a mild learning disability. Two months later he developed coarse tremors in the upper extremities. After 6 months, he was evaluated at a local family care center and was found to have symmetrical tremors in the upper extremities, and difficulty with rapid alternating movements. Shortly thereafter, he was admitted to the local university hospital for massive hydrocephalus with aqueduct obstruction by an unresectable tectal tumor. On the same day, he underwent placement of a ventriculoperitoneal shunt, which relieved his hydrocephalus. The evaluation at the local university hospital provided the final diagnosis of tectal glioma, most likely low-grade astrocytoma. Biopsy and surgery were not recommended, but the patient was advised to have periodical follow-ups. Three months later, he underwent neurosurgical consultation with no recommendation for surgical intervention except for occasional shunt revision. In April 1995 he was consulted by a neuro-oncologist at a leading neuro-oncology treatment center in the US. Since the tumor did not change in size, there was no further recommendation for treatment, but only for periodical follow-up.

Magnetic resonance imaging (MRI) of the head of September 30,1997 , revealed approximately the same size tectal tumor measuring $17 \times 17 \times 15 \mathrm{~mm}$. MRI of June 21,2001 , indicated transformation to a vascular tumor and increasing tumor size. The patient underwent neurosurgical consultation at a state university hospital, and his case was discussed by the tumor board, which concluded that the tumor had acquired high-grade glioma characteristics, and that the patient should receive radiation therapy and chemotherapy with temozolomide. Surgical resection was not recommended. Shortly thereafter, in July 2001, he underwent consultation at a university hospital with the recommendation of radiation therapy without chemotherapy.

On August 7, 2001, the patient was admitted for evaluation at Burzynski Clinic in Houston, Tex. He was complaining of occasional headaches below the occipital area, occasional blurred vi- sion, and slight ptosis of the left eyelid. There was no significant past medical history, and no neurofibromatosis, type 1 . His physical examination was grossly within normal range. His Karnofsky Performance Status was 80. Baseline MRI of July 27, 2001, revealed over $60 \%$ increase in the size of the contrast-enhancing lesion compared to the prebaseline study of June 21, 2001.

On August 14, 2001, the patient was admitted for treatment with ANP A10 and AS2-1 infusions according to Protocol BT-09. After initial progression, partial response was observed on August 14, 2002, followed by CR on December 4, 2002. Five months later the patient was eligible for maintenance oral treatment with ANP A10 and AS2-1 capsules.

The study was listed by the National Cancer Institute and reviewed by an independent institutional review board (BRI Institutional Review Board), and all of the study subjects read, understood, and signed a written informed consent prior to enrollment. This study was conducted in accordance with the US code of federal regulations, Title 21, Parts 11, 50, 56 and 312; the Declaration of Helsinki (1964) including all amendments and revisions; the Good Clinical Practices: Consolidated Guideline (E6): International Conference on Harmonization, and the FDA's Guidance for the Industry. The study was sponsored by the Burzynski Research Institute and conducted by the Burzynski Clinic in Houston, Tex. The patient did not pay for the investigational agents. Treatment data are summarized in table 1 .

Before coming for the treatment with ANP, the patient was taking oral dexamethasone $16 \mathrm{mg}$ daily. He continued such treatment together with intravenous ANP, and 2 weeks later, he increased the dose to $24 \mathrm{mg}$ orally daily to reduce intracranial pressure. After 2 months, the dose of dexamethasone was decreased again to $12 \mathrm{mg}$ daily, and the patient began gradual tapering of the doses of dexamethasone until he discontinued 2 months later.

From August 14, 2001 to September 2, 2001, the patient was also taking oral famotidine $40 \mathrm{mg}$ daily. Three and a half months after the treatment start, he developed an infection of his subclavian catheter, for which he was treated with intravenous antibiotics (vancomycin, gentamicin and rifampin). The infection resolved within a week. He was also periodically taking potassium, magnesium, calcium and phosphate supplements due to electrolyte abnormalities.

Adverse events according to CTCAE v3.0 included: hypernatremia (two events of grade 3 , one event of grade 2 , four events of grade 1), one case of fatigue (grade 2), and one allergic reaction (grade 1). All adverse events were reversible.

Baseline MRI of the head revealed a contrast-enhancing mass measuring $2.2 \times 2.2 \mathrm{~cm}$, located in the tectum. After 2 months of treatment there was an increase in the size of the lesion by $45 \%$ as evidenced by MRI of October 12, 2001. The tumor growth stabilized after the dose of ANP A10 was increased, as indicated by three follow-up MRIs at 1-month intervals. An MRI of the head after 7 months of treatment revealed an approximate $20 \%$ decrease in the tumor size, and since then there was gradual shrinkage of the lesion evidenced by MRIs taken at 1- to 2-month intervals. At 1 year, there was over $60 \%$ decrease in tumor size, which qualified the patient for partial response. Finally, on December 4, 2002 , there was no visible tumor on the MRI. He was followed by MRIs every 2-3 months, as required by protocol, with no sign of tumor recurrence (fig. 1). Five years after treatment discontinuation, the MRI on November 19, 2008, revealed a small cystic for- 
Table 1. Treatment data

\begin{tabular}{|c|c|c|c|c|c|c|}
\hline \multirow[t]{2}{*}{ Date } & \multirow[t]{2}{*}{ Comment } & \multicolumn{2}{|c|}{$\begin{array}{l}\text { ANP A10 and AS2-1 } \\
\text { i.v., g/kg/day }\end{array}$} & \multicolumn{2}{|c|}{$\begin{array}{l}\text { ANP A10 and AS2-1 } \\
\text { oral, g/kg/day }\end{array}$} & \multirow[t]{2}{*}{ Dexamethasone oral, mg/day } \\
\hline & & A10 & AS2-1 & A10 & AS2-1 & \\
\hline $\begin{array}{l}\text { August 14, } 2001 \text { till } \\
\text { August 29, } 2001\end{array}$ & $\begin{array}{l}\text { escalation and } \\
\text { target dose }\end{array}$ & 8.2 & 0.4 & - & - & 16 \\
\hline \multicolumn{2}{|l|}{ August 30, 2001} & 8.2 & 0.4 & - & - & 24 \\
\hline $\begin{array}{l}\text { October } 18,2001 \text { to } \\
\text { December } 1,2001\end{array}$ & $\begin{array}{l}\text { increase of the } \\
\text { dosage of A10 }\end{array}$ & 12.5 & 0.4 & - & - & $\begin{array}{l}\text { reduced from } 24 \text { to } 12 \text { on October } 26 \text {, } \\
2001 \text { followed by a gradual decrease } \\
\text { in the dosage from November } 1,2001 \\
\text { and permanent discontinuation on } \\
\text { December } 26,2001\end{array}$ \\
\hline \multicolumn{2}{|l|}{$\begin{array}{l}\text { December 22, } 2001 \text { to } \\
\text { April 20, } 2003\end{array}$} & $\begin{array}{l}8.0-14.7 \\
\text { median } 11.6\end{array}$ & $\begin{array}{l}0.3-0.4 \\
\text { median } 0.34\end{array}$ & - & - & - \\
\hline \multicolumn{2}{|l|}{ April 20, 2003} & discor & tinued & - & - & - \\
\hline \multicolumn{2}{|l|}{$\begin{array}{l}\text { April 22, } 2003 \text { to } \\
\text { December 26, } 2003\end{array}$} & - & - & 0.26 & 0.26 & - \\
\hline \multicolumn{2}{|l|}{ December 27, 2003} & - & - & \multicolumn{2}{|c|}{ discontinued } & - \\
\hline
\end{tabular}

Patient's date of birth: February 19, 1981. Off treatment December 2, 2001 to December 21, 2001 due to catheter infection, and from August 27, 2002 to September 6, 2002 and from March 14, 2003 to March 24, 2003 due to suspected gastrointestinal infection.

mation measuring $0.5 \times 0.4 \mathrm{~cm}$. It persisted without any treatment until December 2010, when the MRI did not show any lesions, confirmed by the most recent MRI in December 2012. The MRIs were performed and evaluated by external radiologists. After completion of the treatment, all scans were submitted for central radiology review at Innovative Radiology in Houston, Tex., USA. It was the opinion of the central radiology review that the patient obtained a CR, and the residual changes represented posttherapy gliosis and calcifications. The response was judged by the decrease and disappearance of the contrast-enhancing and nonenhancing tumor and by the negative positron emission tomography (PET) scan. CR required confirmation by a second MRI performed at least 4 weeks later. Post-therapy gliosis and calcifications present on the MRI of December 8, 2012, were not considered to represent active tectal glioma. The patient's response data are summarized in table 2 . The patient became asymptomatic after 7 months of treatment after his MRI of the head revealed the decreased tumor size. He continues to live a normal life and work full-time at present. He has a good family life and became the father of two children.

\section{Discussion}

Tectal gliomas occupy the tectum or quadrigeminal plate, which is composed of the superior and inferior colliculi. Since they lie posterior to the cerebral aqueduct, they frequently cause obstruction of the circulation of cerebrospinal fluid and hydrocephalus [3]. There is usually a benign course of the disease but, unfortunately, tectal glioma is known as the smallest tumor in the body that can lead to death of the patient [1]. The initial clinical history of the patient described in this article is typical for benign tectal glioma. It is characterized by stable tumor size over a long period of time and uncommon cranial nerve symptoms. The management of these tumors is typically limited to placement of a ventriculoperitoneal shunt. In this case the patient had relatively minor symptoms during the first 8 months, but required a ventriculoperitoneal shunt after he developed massive hydrocephalus. There was no significant change in the tumor size for over 6 years, but after that there was over $60 \%$ increase in tumor size and signs of malignant transformation by MRI. Surgery and biopsy were not advised in this case since some reports indicated rapid tumor growth after surgical intervention [6, 7]. Based on prior experience in the treatment of both benign and aggressive pediatric gliomas, the patient was admitted to clinical study according to Protocol BT-09 [4, 5, 8]. He accomplished durable CR with long-term survival (over 20 years from tumor diagnosis). He lives a normal, productive life and did 

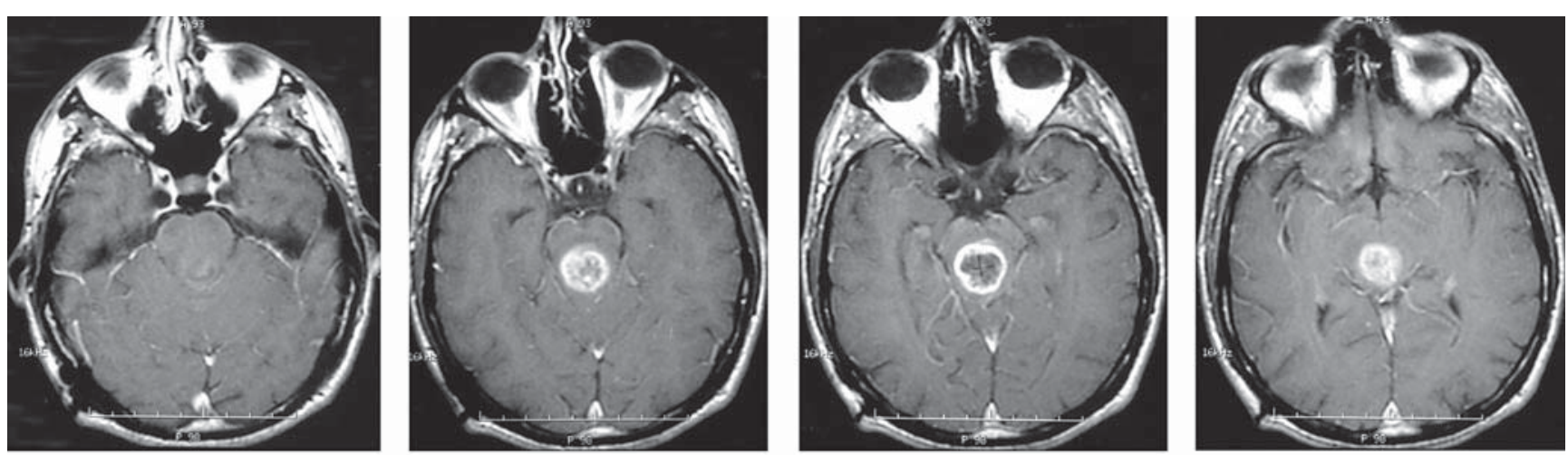

Baseline MRI, July 27, 2001
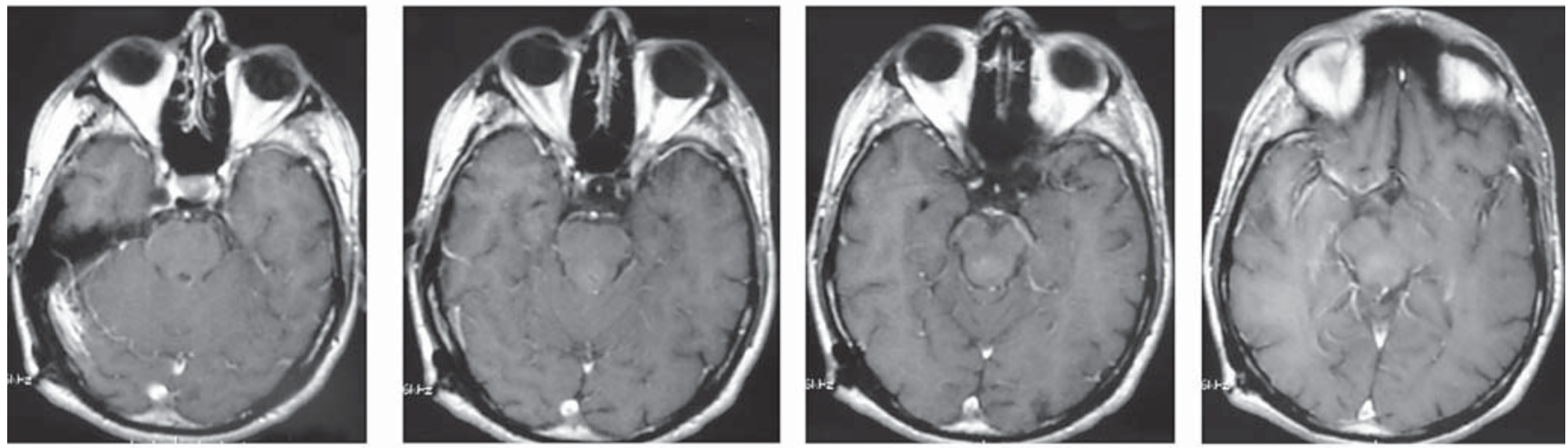

MRI, December 4, 2002
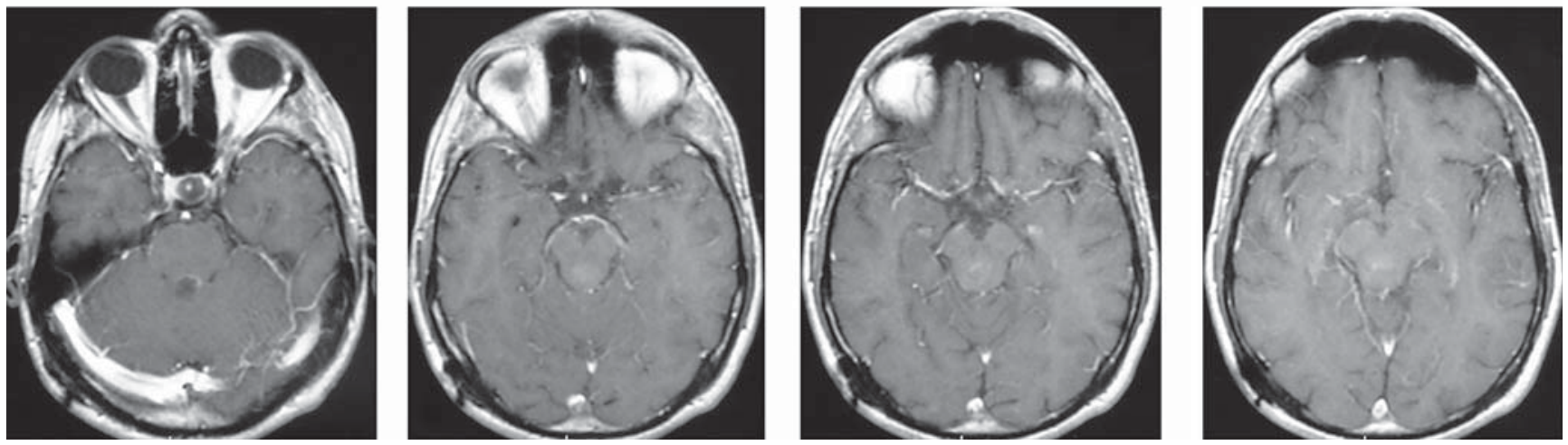

MRI, January 13, 2003

Fig. 1. Baseline MRI and follow-up postcontrast MRIs indicating response to treatment.

not show any chronic toxicity. The patient was not diagnosed with neurofibromatosis, type 1 , which could promote spontaneous regression. His last follow-up was on September 15, 2014. Biopsy and surgery were not recommended by neurosurgical consultants, and it is disappointing that pathology data are not available. The au- thors decided to delay writing this report, to make sure that the results would be most convincing. This report suggests that it is possible to obtain long-term overall survival in patients suffering from tectal glioma with an aggressive course of the disease. The results of phase II studies of ANP are described in a number of articles [8-10]. 
Table 2. Response data

\begin{tabular}{|c|c|c|c|c|c|}
\hline Date & MRI enhancing & $\begin{array}{l}\text { MRI } \\
\text { nonenhancing }\end{array}$ & PET & Response & $\begin{array}{l}\text { Confirmation } \\
\text { by CRR }\end{array}$ \\
\hline July 27, 2001 & $2.1 \times 2.2 \mathrm{~cm}$ & & & baseline & \\
\hline October 12, 2001 & $\begin{array}{l}\text { increased by } 45 \% \\
2.6 \times 2.7 \mathrm{~cm}\end{array}$ & increased & & $\begin{array}{l}\text { increasing } \\
\text { tumor size }\end{array}$ & increased \\
\hline November 9, 2001 & stable $2.6 \times 2.4 \mathrm{~cm}$ & stable & & & increased \\
\hline January 17, 2002 & stable $2.6 \times 2.4 \mathrm{~cm}$ & stable & & & stable \\
\hline February 27, 2002 & decreased by $20 \% 2.5 \times 2.2 \mathrm{~cm}$ & decreased & & $\mathrm{SD}$ & decreased \\
\hline August 14, 2002 & decreased by $64 \% 1.5 \times 1.1 \mathrm{~cm}$ & decreased & & PR & $\mathrm{PR}$ \\
\hline
\end{tabular}

Patient's date of birth: February 19, 1981. CR = Complete response; CRR = central radiology review; $\mathrm{PR}=$ partial response; $\mathrm{SD}=$ stable disease.

\section{Disclosure Statement}

The clinical trial was sponsored by the Burzynski Research Institute (BRI) Inc. S.R.B. is chairman of the Board of Directors and President of BRI Inc. G.S.B. is a member of the Board of Directors of BRI Inc. T.J. is the Vice President of Clinical Trials at BRI Inc. All authors are employed by Burzynski Clinic. Randall A. Stenoien, MD, who is employed by Innovative Radiology of Houston, Tex., provided the central radiology review. Innovative Radiology is not associated with Burzynski Clinic or BRI.

\section{References}

1 Stark AM, Fritsch MJ, Claviez A, et al: Management of tectal glioma in childhood. Pediatr Neurol 2005;33:33-38.

$\checkmark 2$ Bowers DC, Georgiades C, Aronson LJ, et al: Tectal gliomas: natural history of an indolent lesion in pediatric patients. Pediatr Neurosurg 2000;32:24-29.

-3 Dağlioğlu E, Cataltepe O, Akalan N: Tectal gliomas in children: the implications for natural history and management strategy. Pediatr Neurosurg 2003;38:223-231.

4 Burzynski SR: The present state of antineoplaston research (1). Integr Cancer Ther 2004; $3: 47-58$.
5 Burzynski SR: Treatment for astrocytic tumors. Pediatr Drugs 2006;8:167-178.

6 Matsuno A, Nagashima H, Ishii H, et al: Aggressive and invasive growth of tectal glioma after surgical intervention and chemoradiotherapy. Br J Neurosurg 2006;20:246-249.

7 Wang C, Zhang J, Liu A, et al: Surgical treatment of primary midbrain gliomas. Surg Neurol 2000;53:41-51.

-8 Burzynski SR, Janicki TJ, Burzynski GS, Marszalek A: Long-term survival ( $>13$ years) in a child with recurrent diffuse intrinsic pontine glioma: a case report. J Pediatr Hematol Oncol 2014;36:e433-e439.
9 Burzynski SR, Janicki TJ, Burzynski GS, Marszalek A: The response and survival of children with recurrent diffuse intrinsic pontine glioma based on phase II study of antineoplastons A10 and AS2-1 in patients with brainstem glioma. Childs Nerv Syst 2014;30: 2051-2061.

10 Burzynski SR, Janicki TJ, Burzynski GS, Marszalek A: A phase II study of antineoplastons A10 and AS2-1 in children with highgrade glioma. Final report (Protocol BT-06) and review of recent trials. J Cancer Ther 2014:5:565-577. 